\title{
บUsisersily
}

\section{Comparative in vitro evaluation of glimepiride containing nanosuspension drug delivery system developed by different techniques}

Bose, S., Sharma, P., Mishra, V., Patial, S., Saraogi, G. K., Tambuwala, M. M., \& Dua, K. (2021). Comparative in vitro evaluation of glimepiride containing nanosuspension drug delivery system developed by different techniques. Journal of Molecular Structure, 1231, [129927]. https://doi.org/10.1016/j.molstruc.2021.129927

Link to publication record in Ulster University Research Portal

\section{Published in:}

Journal of Molecular Structure

Publication Status:

Published (in print/issue): 05/05/2021

DOI:

10.1016/j.molstruc.2021.129927

\section{Document Version}

Author Accepted version

\section{General rights}

Copyright for the publications made accessible via Ulster University's Research Portal is retained by the author(s) and / or other copyright owners and it is a condition of accessing these publications that users recognise and abide by the legal requirements associated with these rights.

\section{Take down policy}

The Research Portal is Ulster University's institutional repository that provides access to Ulster's research outputs. Every effort has been made to ensure that content in the Research Portal does not infringe any person's rights, or applicable UK laws. If you discover content in the Research Portal that you believe breaches copyright or violates any law, please contact pure-support@ulster.ac.uk. 
Comparative in vitro evaluation of glimepiride containing nanosuspension drug delivery system developed by different techniques

Sujit Bose ${ }^{1}$, Pooja Sharma ${ }^{2}$, Vijay Mishra ${ }^{1 *}$, Swati Patial ${ }^{3}$, Gaurav K. Saraogi ${ }^{4}$, Murtaza M. Tambuwala ${ }^{5}$, Kamal Dua ${ }^{6}$

${ }^{1}$ School of Pharmaceutical Sciences, Lovely Professional University, Phagwara (Punjab), India

${ }^{2}$ Abhilashi College of Pharmacy, Narchowk, Mandi (H.P.), India

${ }^{3}$ Overseas Healthcare Pvt. Ltd., Phillaur (Punjab), India

${ }^{4}$ NMIMS, School of Pharmacy and Technology Management, Shirpur (Maharastra), India

${ }^{5}$ School of Pharmacy and Pharmaceutical Science, Ulster University, Coleraine, County Londonderry, Northern Ireland BT52 1SA, UK

${ }^{6}$ Discipline of Pharmacy, Graduate School of Health, University of Technology Sydney, Sydney, NSW 2007, Australia

\section{*Corresponding author}

Dr. Vijay Mishra

School of Pharmaceutical Sciences,

Lovely Professional University, Phagwara (Punjab) 144411, India

Email: vijaymishra2@gmail.com 
Abstract: The present study was aimed to develop the Glimepiride (GLM) loaded nanosuspension by different methods for increasing the solubility of GLM. Twelve formulations were prepared by combination method (FG), which included antisolvent precipitation method followed by sonication (Method 1) selecting drug and polymer in ratio of 1:10, 1:20 and 1:30. Further 6 formulations were prepared by nanoprecipitation method (Fg) (Method 2) selecting drug and polymer in ratio of 1:10, 1:20 by using different polymers like polyvinyl pyrolidone (PVP K30), and poly(ethylene glycol) (PEG) such as PEG6000 and PEG400. The GLM nanosuspensions prepared by different techniques were evaluated by optical microscopy, percent entrapment efficiency (\%EE), particle size analysis, zeta potential, transmission electron microscopy (TEM) and in vitro dissolution. FG1 formulation was found to be better formulation showing $82.04 \%$ EE, $129-180 \mathrm{~nm}$ particle size range, $30.16 \mathrm{mV}$ zeta potential, 0.253 polydispersity index (PDI) and $86.76 \%$ drug release as compared to Fgii formulation having \%EE, average particle size, zeta potential, PDI value and drug release as $80.03 \%, 72-383 \mathrm{~nm},-22.19 \mathrm{mV}, 0.358$ and $74.77 \%$, respectively. On the basis of results obtained from different studies, it can be concluded that GLM nanosuspension prepared by combination technique (FG) shows good solubility and dissolution than those prepared by nanoprecipitation technique $(\mathrm{Fg})$, hence the combination technique is found to be a preferred technique to prepare GLM nanosuspension over nanoprecipitation technique.

Keywords: Diabetes mellitus; Nanosuspension; Antidiabetic; Glimepiride; Polymers; Drug delivery. 


\section{Introduction}

Diabetes mellitus (DM) is chronic, life-long endocrine and metabolic disorder, which occurs due to the defect in insulin secretion and its action $[1,2]$. The DM can be classified as type 1 i.e. insulin-dependent, type 2 i.e. non-insulin dependent and gestational diabetes (in pregnant women) [3]. According to International Diabetes Federation (IDF), people with diabetes in India will reach 80 million by the year 2025 . One survey has stated that $4 \%$ of adults in India are suffering from diabetes in the year 2000 and it is expected to increase up to $6 \%$ from the year $2025[4,5]$.

Since 1995 Food and Drug Administration (FDA) approved various anti-diabetic medications for the management of type-2 DM. Several types of oral anti-hyperglycaemic agents are used as monotherapy or combination therapy to treat DM [6]. These include meglitinides, biguanides, sulphonylurea, and aglucosidase inhibitors [7]. In oral hypoglycemic therapy, the sulphonylureas are class first anti-diabetic drugs generally used in the treatment of type- 2 DM. They increase the insulin secretion by acting on $\beta$-cells of pancreas [8].

Biopharmaceutics Classification System (BCS) is fundamentally a classification system based on 2 major parameters e.g. solubility and permeability, which determine the fraction of drug dose absorbed and consequently its chances to be bioavailable. On the basis of these parameters, drugs can be categorized into four main classes- (i) BCS Class I (high soluble/high permeable drugs), (ii) BCS Class II (low soluble/high permeable drugs), (iii) BCS Class III (high soluble/low permeable drugs) and (iv) BCS Class IV (low soluble/low permeable drugs) $[9,10]$. The BCS is based on the tube model of the intestinal lumen. This model considers constant drug permeability along the intestines, a plug flow fluid with the suspended drug particles moving with the fluid, and dissolution in the small particle limit [11]. The major advances associated with the BCS concern the extensive work on dissolution 
of poorly absorbed BCS class II drugs in nutritional liquids and biorelevant media for the accurate prediction of the rate and the extent of oral absorption [12].

Glimepiride (GLM), an anti-diabetic drug of class sulphonylurea belonging to BCS class-II is mostly used for the treatment of type-2 DM [13]. The reported solubility of GLM in aqueous media with $\mathrm{pH} 7.0$ and $\mathrm{pH} 6.8$ is $1.2 \mu \mathrm{g} / \mathrm{mL}$ and $0.87 \mu \mathrm{g} / \mathrm{mL}$, respectively, which shows $\mathrm{pH}$-dependent solubility behavior. Poor solubility, a major problem of GLM results in poor dissolution and bioavailability. Due to limited aqueous solubility of class II drugs, dissolution in gastric media acts as rate-limiting step for absorption [14]. The GLM in tablet form has some problems like poor solubility, incomplete dissolution, and low efficacy [15]. Marketed formulations of GLM provide an immediate release with peak serum concentrations achieved 2-3 $\mathrm{h}$ after oral administration, resulting into a fluctuating release profile. Such fluctuations can be minimized by preparing its sustained and prolonged delivery systems, which will be able to maintain steady state drug level in plasma. Such drugs necessitate the preparation of suitable dosage forms which can improve solubility as well as therapeutic efficacy $[14,16]$. Nanotechnology based promising approaches of nanosuspension formulation not only solve the problem of solubility and bioavailability but also can alter the pharmacokinetics and help in improving the safety and efficacy of the drug [15].

Nanosuspension is the novel approach to overcome the problem of low dissolution rate and compromised oral bioavailability and reduce the delivery issues by maintaining the drug in preferred crystalline state [17]. Nanosuspension signifies sufficient safety and efficacy [18]. Nanosuspension is a biphasic system composed of the finely divided insoluble solid drug of size range $10^{-9} \mathrm{~m}$ in a liquid medium which is stabilised by surfactants. Because of reduced size of the drug, there is an increase in solubility. So by the fabrication of nanosuspension, the solubility of a poorly soluble drug can be increased $[19,20]$.

Nanosuspensions offer potential advantages such as reduction of dose as well as cost of therapy, avoiding dose dumping in the body, minimizing fast/fed state plasma level 
fluctuation and intersubject variability. These advantages have driven towards faster development of nanosuspension technology during last few decades [21]. Various methods are utilized for the formation of nanosuspension [22-27], including cosolvency [28], solid dispersion [29], inclusion complexation [30], cryogenic technique [31], salt formation [32], solvent-antisolvent method [33,34], supercritical fluid process [35], emulsification-solvent evaporation technique [36] and media milling techniques [37].

The aim of the present work was to compare the in vitro profile of GLM containing nanosuspensions prepared by different techniques giving emphasis on the particle size control during the preparation of nanosuspensions. From pre-screening study, two techniques were selected such as combination technique, which includes antisolvent evaporation followed by sonication and nanoprecipitation technique. The characterization and evaluation were done by optical microscopy, drug entrapment efficiency, particle size analysis, zeta potential, in vitro dissolution and transmission electron microscopy (TEM).

\section{Materials and Methods}

\subsection{Materials}

Glimepiride was kindly provided by Swiss Garnier Life Sciences (Mehatpur, Una, Himachal Pradesh, India) as a gift sample. Acetone, dichloromethane, polyethylene glycol (PEG400, PEG6000), Span 80, Tween 80, polyvinyl pyrolidone (PVP K30), microcrystalline cellulose and sodium dodecyl sulphate were purchased from Loba Chemie Pvt. Ltd. (Mumbai, India). All other chemicals and reagents were of analytical grade.

\subsection{Methods}

\subsubsection{Screening of method for fabrication of nanosuspension}

\subsubsection{Combination technique (Method 1)}

In this method nanosuspension formulation (FG) was prepared by anti-solvent evaporation followed by sonication technique. Briefly, appropriate amount of drug was taken and dissolved in water immiscible anti-solvent. Then, $1 \mathrm{~mL}$ of GLM solution was injected in 
to deionized water with or without polymers or surfactants at $4 \pm 0.5{ }^{\circ} \mathrm{C}$ with rapid stirring at $1200 \mathrm{rpm}$ followed by intense sonication [38]. The drug:polymer ratio and formulations for different batches prepared by combination technique were represented in Table 1A and

Table 1B, respectively.

Table 1A Screening the ratio of components for formulation prepared by combination technique

\begin{tabular}{|c|c|c|}
\hline Batch code & Components & Ratio \\
\hline FG1 & Glimepiride: PEG 6000 & $1: 10$ \\
\hline FG2 & Glimepiride: PEG 6000 & $1: 20$ \\
\hline FG3 & Glimepiride: PEG 6000 & $1: 30$ \\
\hline FG4 & Glimepiride: PVP K30 & $1: 10$ \\
\hline FG5 & Glimepiride: PVP K30 & $1: 20$ \\
\hline FG6 & Glimepiride: PVP K30 & $1: 30$ \\
\hline FG7 & Glimepiride: PEG 400 & $1: 10$ \\
\hline FG8 & Glimepiride: PEG 400 & $1: 20$ \\
\hline FG9 & Glimepiride: PEG 400 & $1: 30$ \\
\hline FG10 & Glimepiride:PEG6000:PVPK30 & $1: 05: 05$ \\
\hline FG11 & Glimepiride:PEG6000:PEG400 & $1: 10: 10$ \\
\hline FG12 & Glimepiride:PEG400: PVPK30 & $1: 15: 15$ \\
\hline & & \\
\hline & & \\
\hline & & \\
\hline & & \\
\hline & & \\
\hline & & \\
\hline & & \\
\hline & & \\
\hline & & \\
\hline & & \\
\hline & & \\
\hline & & \\
\hline & & \\
\hline & & \\
\hline & & \\
\hline & & \\
\hline
\end{tabular}

Table 1B Formulation details of batches (FG1-FG12) prepared by combination technique

\begin{tabular}{|l|c|c|c|c|c|c|}
\hline $\begin{array}{l}\text { Batch } \\
\text { code }\end{array}$ & $\begin{array}{c}\text { Glimepiride } \\
(\mathrm{mg})\end{array}$ & $\begin{array}{c}\text { PEG 6000 } \\
(\mathrm{mg})\end{array}$ & $\begin{array}{c}\text { PEG 400 } \\
(\mathrm{mg})\end{array}$ & $\begin{array}{c}\text { PVP K30 } \\
(\mathrm{mg})\end{array}$ & $\begin{array}{c}\text { Water } \\
(\mathrm{mL})\end{array}$ & $\begin{array}{c}\text { Homogenization } \\
\text { speed (rpm) }\end{array}$ \\
\hline FG1 & 1 & 10 & - & - & 40 & 1200 \\
\hline FG2 & 1 & 20 & - & - & 40 & 1200 \\
\hline
\end{tabular}




\begin{tabular}{|l|c|c|c|c|c|c|}
\hline FG3 & 1 & 30 & - & - & 40 & 1200 \\
\hline FG4 & 1 & - & - & 10 & 40 & 1200 \\
\hline FG5 & 1 & - & - & 20 & 40 & 1200 \\
\hline FG6 & 1 & - & - & 30 & 40 & 1200 \\
\hline FG7 & 1 & - & 10 & - & 40 & 1200 \\
\hline FG8 & 1 & - & 20 & - & 40 & 1200 \\
\hline FG9 & 1 & - & 30 & - & 40 & 1200 \\
\hline FG10 & 1 & 05 & - & 05 & 40 & 1200 \\
\hline FG11 & 1 & 10 & 10 & - & 40 & 1200 \\
\hline FG12 & 1 & - & 15 & 15 & 40 & 1200 \\
\hline
\end{tabular}

\subsubsection{Nanoprecipitation technique (Method 2)}

In this method, the drug GLM was dissolved in methanol (organic phase). The polymer PVPK30, PEG6000 and PEG400 were added to $40 \mathrm{~mL}$ of distilled water (aqueous phase). The organic phase was drop wise added to the aqueous phase with syringe at room temperature and stirred at $1200 \mathrm{rpm}$ for $1 \mathrm{~h}$ on magnetic stirrer [39]. The drug:polymer ratio and formulations for different batches prepared by nanoprecipitation technique (Fg) were represented in Table $\mathbf{2 A}$ and Table $\mathbf{2 B}$, respectively.

Table 2A Screening the ratio of components for formulations prepared by nanoprecipitation technique

\begin{tabular}{|c|c|c|}
\hline Batch code & Components & Ratio \\
\hline Fgi & Glimepiride: PEG 6000 & $1: 10$ \\
\hline Fgii & Glimepiride: PEG 6000 & $1: 20$ \\
\hline Fgiii & Glimepiride: PVP K30 & $1: 10$ \\
\hline Fgiv & Glimepiride: PVP K30 & $1: 20$ \\
\hline
\end{tabular}




\begin{tabular}{|c|c|c|}
\hline Fgv & Glimepiride: PEG 400 & $1: 10$ \\
\hline Fgvi & Glimepiride: PEG 400 & $1: 20$ \\
\hline
\end{tabular}

Table 2B Formulation details of batches (Fgi-Fgvi) prepared by nanoprecipitation technique

\begin{tabular}{|c|c|c|c|c|c|c|}
\hline $\begin{array}{l}\text { Batch } \\
\text { code }\end{array}$ & $\begin{array}{c}\text { Glimepiride } \\
\text { (mg) }\end{array}$ & $\begin{array}{c}\text { PEG } 6000 \\
(\mathrm{mg})\end{array}$ & $\begin{array}{c}\text { PEG } 400 \\
(\mathrm{mg})\end{array}$ & $\begin{array}{c}\text { PVP K30 } \\
\text { (mg) }\end{array}$ & $\begin{array}{l}\text { Water } \\
(\mathrm{mL})\end{array}$ & $\begin{array}{c}\text { Homogenization } \\
\text { speed (rpm) }\end{array}$ \\
\hline Fgi & 1 & 10 & - & - & 40 & 1200 \\
\hline Fgii & 1 & 20 & - & - & 40 & 1200 \\
\hline Fgiii & 1 & - & - & 10 & 40 & 1200 \\
\hline Fgiv & 1 & - & - & 20 & 40 & 1200 \\
\hline Fgv & 1 & - & 10 & - & 40 & 1200 \\
\hline Fgvi & 1 & - & 20 & - & 40 & 1200 \\
\hline
\end{tabular}

\subsubsection{Determination of drug entrapment efficiency}

The entrapment efficiency of GLM loaded nanosuspensions was evaluated indirectly by estimating the unentrapped GLM. Briefly, the amount of unentrapped drug was first separated from nanosuspension by centrifugation at $20000 \mathrm{rpm}$ for $30 \mathrm{~min}$ at $4 \pm 0.5^{\circ} \mathrm{C}$ using cool ultracentrifuge and was analyzed from supernatant spectrophotometrically (1601 UVvis spectrophotometer, Shimadzu, Kyoto, Japan) at $\lambda_{\max } 228 \mathrm{~nm}(\mathrm{n}=3)$ [40-42]. The percent entrapment efficiency $(\% \mathrm{EE})$ was determined by applying following equation:

$$
\% \text { Entrapment efficiency }(\% \mathrm{EE})=\frac{(\text { Total drug taken- Drug in supernatant liquid })}{\text { Total drug taken }} \times 100
$$

\subsubsection{Particle size and zeta potential}


The nanosuspensions prepared by combination technique and nanoprecipitation technique were subjected to particle size analysis using Beckman Coulter (RQ-121 D, Beckman Coulter India Pvt. Ltd., Mumbai, India) [43,44].

\subsubsection{Transmission electron microscopy}

Another technique, transmission electron microscopy (TEM) was employed for the characterization of the developed nanosuspensions after drying a drop of a sample on carbon grid and negatively stained with phosphotungastic acid (1\%) by the metal shadowing techniques (Philips CM-10 TEM, Eindhoven, The Netherlands). The microphotographs were captured at different magnifications of 19000-50000 X.

\subsubsection{In vitro drug release studies}

Drug release profiles of nanosuspensions prepared by different techniques were observed using USP type II dissolution apparatus at a rate of $50 \mathrm{rpm}$ employing phosphate buffer saline (PBS) $\mathrm{pH} 6.8$ as dissolution medium at $37 \pm 0.5{ }^{\circ} \mathrm{C}$. A sample $(5 \mathrm{~mL})$ was withdrawn at different time intervals ranging from 5-60 min. The same volume was replenished with fresh dissolution medium. The amount of released GLM was analyzed spectrophotometrically (1601 UV-Vis Spectrophotometer, Shimadzu, Kyoto, Japan) at $\lambda_{\max }$ $228 \mathrm{~nm}(\mathrm{n}=3)[45,46]$.

\subsubsection{Statistical analysis}

Results were depicted as mean $\pm \mathrm{SD}$ from at least three measurements $(\mathrm{n}=3)$. A P-value $<0.05$ was considered statistically significant.

\section{Results and Discussion}

\subsection{Formulation development trials}

Drug-excipient compatibility study was carried out using drug and different excipients mixture in $1: 1$ ratio by placing the mixtures in glass containers stored at $40 \pm 1{ }^{\circ} \mathrm{C}$. Observations were made on predetermined day interval physically for any change in color, appearance, state and lump formation (Table S1). 
Drug-polymer compatibility study is an important parameter in the development of stable dosage form. Compatibility of GLM with other excipients of nanosuspension was analyzed on $15^{\text {th }}$ day by using Fourier-transform infrared spectroscopy (FTIR, Schimadzu, Model 8400, Japan) with pressed pellet technique using potassium bromide. Samples were scanned in the region of $4000-400 \mathrm{~cm}^{-1}$. The effect of the excipients on the major peaks of GLM was observed to find the compatibility of the drug and excipients. The undisturbed peak of drug signifies compatibility of the drug with the excipients [14] (Fig. S1).

\subsubsection{Optimization of nanosuspension formulation prepared by combination technique and by nanoprecipitation technique}

The design of optimization for combination technique contained two independent variables $(\mathrm{X} 1, \mathrm{X} 2)$ and one dependent variable $(\mathrm{Y} 1)$. The $\mathrm{X} 1$ and $\mathrm{X} 2$ variables represented drug $(\% \mathrm{w} / \mathrm{w})$ and polymer $(\% \mathrm{w} / \mathrm{w})$, respectively, whereas, the $\mathrm{Y} 1$ variable was $\% \mathrm{EE}$. Accordingly, 12 formulations were formulated and analyzed for EE (Table 3). Similarly, the design of optimization for nanoprecipitation technique contained two independent variables (Xi, Xii) and one dependent variable (Yi). The Xi and Xii variables represented drug (\% $\mathrm{w} / \mathrm{w})$ and polymer $(\% \mathrm{w} / \mathrm{w})$ respectively, whereas, the Yi variable was \%EE. Accordingly, 6 formulations were formulated and analyzed for EE (Table 4).

Table 3. Factor combination and responses for combination technique

\begin{tabular}{|c|c|c|c|c|}
\hline $\begin{array}{l}\text { Batch } \\
\text { code }\end{array}$ & $\begin{array}{l}\text { Amount of drug } \\
(\mathrm{mg})(\mathrm{X} 1)\end{array}$ & $\begin{array}{c}\text { Amount of polymer } \\
\text { (mg) (X2) }\end{array}$ & $\begin{array}{c}\text { Homogenization } \\
\text { speed (rpm) }\end{array}$ & $\begin{array}{r}\text { Entrapment } \\
\text { efficiency }(\%)\end{array}$ \\
\hline FG1 & $1 \mathrm{mg}$ Glimepiride & $10 \mathrm{mg}$ (PEG6000) & 1200 & 82.04 \\
\hline FG2 & $1 \mathrm{mg}$ Glimepiride & $20 \mathrm{mg}$ (PEG6000) & 1200 & 43.63 \\
\hline FG3 & $1 \mathrm{mg}$ Glimepiride & $30 \mathrm{mg}$ (PEG6000) & 1200 & 32.42 \\
\hline FG4 & $1 \mathrm{mg}$ Glimepiride & $10 \mathrm{mg}$ (PVPK30) & 1200 & 78.44 \\
\hline FG5 & $1 \mathrm{mg}$ Glimepiride & $20 \mathrm{mg}$ (PVPK30) & 1200 & 74.02 \\
\hline
\end{tabular}




\begin{tabular}{|c|c|c|c|c|}
\hline FG6 & $1 \mathrm{mg}$ Glimepiride & $30 \mathrm{mg}$ (PVPK30) & 1200 & 61.23 \\
\hline FG7 & $1 \mathrm{mg}$ Glimepiride & $10 \mathrm{mg}$ (PEG400) & 1200 & 55.61 \\
\hline FG8 & $1 \mathrm{mg}$ Glimepiride & $20 \mathrm{mg}$ (PEG400) & 1200 & 33.65 \\
\hline FG9 & $1 \mathrm{mg}$ Glimepiride & $30 \mathrm{mg}$ (PEG400) & 1200 & 46.41 \\
\hline FG10 & $1 \mathrm{mg}$ Glimepiride & $10 \mathrm{mg}$ & 1200 & 38.42 \\
& & (PEG6000:PVPK30) & & \\
\hline FG11 & $1 \mathrm{mg}$ Glimepiride & $20 \mathrm{mg}$ & 1200 & 72.42 \\
& & (PEG6000:PEG400) & & \\
\hline FG12 & $1 \mathrm{mg}$ Glimepiride & $30 \mathrm{mg}$ & 1200 & \\
& & (PEG400: PVPK30) & & \\
\hline
\end{tabular}

Table 4. Factor combination and responses for nanoprecipitation technique

\begin{tabular}{|c|c|c|c|c|}
\hline $\begin{array}{l}\text { Batch } \\
\text { code }\end{array}$ & $\begin{array}{l}\text { Amount of drug } \\
(\mathrm{mg})(\mathrm{Xi})\end{array}$ & $\begin{array}{c}\text { Amount of polymer } \\
(\mathrm{mg})(\mathrm{Xii})\end{array}$ & $\begin{array}{c}\text { Homogenization } \\
\text { speed (rpm) }\end{array}$ & $\begin{array}{l}\text { Entrapment } \\
\text { efficiency }(\%)\end{array}$ \\
\hline Fgi & $1 \mathrm{mg}$ Glimepiride & $10 \mathrm{mg}$ PEG 6000 & 1200 & 62.82 \\
\hline Fgii & $1 \mathrm{mg}$ Glimepiride & $20 \mathrm{mg}$ PEG 6000 & 1200 & 80.03 \\
\hline Fgiii & $1 \mathrm{mg}$ Glimepiride & 10 mg PVP K30 & 1200 & 49.24 \\
\hline Fgiv & $1 \mathrm{mg}$ Glimepiride & 20 mg PVP K30 & 1200 & 76.01 \\
\hline Fgv & $1 \mathrm{mg}$ Glimepiride & $10 \mathrm{mg}$ PEG 400 & 1200 & 25.26 \\
\hline Fgvi & $1 \mathrm{mg}$ Glimepiride & $20 \mathrm{mg}$ PEG 400 & 1200 & 63.64 \\
\hline
\end{tabular}

For GLM nanosuspension prepared by combination technique, the appropriate processing was found at $1 \mathrm{mg}$ GLM, $10 \mathrm{mg}$ polymer (PEG6000) and homogenization speed $1200 \mathrm{rpm}$. However, for nanoprecipitation technique the appropriate processing was found at $1 \mathrm{mg}$ GLM, $20 \mathrm{mg}$ polymer (PEG6000) and homogenization speed $1200 \mathrm{rpm}$. The actual drug 
content found in FG1 and Fgii was $82.04 \pm 4.11 \%$ and $80.03 \pm 2.35 \%$, respectively. The optical photomicrographs of formulation FG1 and Fgii at 450X magnification represented the abundance/aggregates of nanoparticles in formulations (Fig. S2).

\subsection{Drug entrapment efficiency}

The drug entrapment efficiency of formulations prepared by combination technique and nanoprecipitation technique is represented in Fig. 1 and Fig. 2. These figures depicted that among all formulations, FG1 and Fgii showed highest \%EE i.e. $82.04 \%$ and $80.03 \%$ prepared by Method 1 and Method 2, respectively.

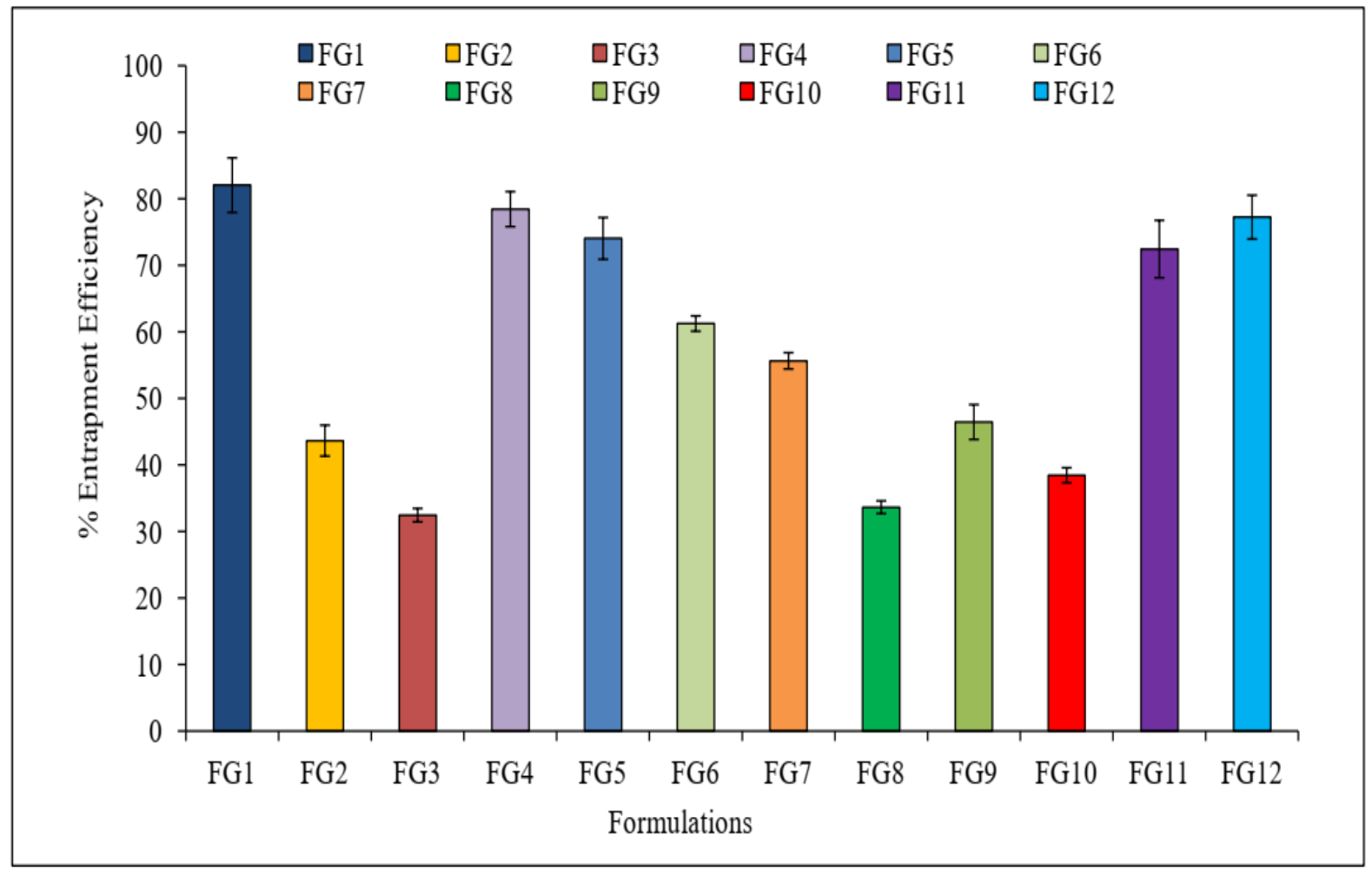

Fig. 1. Percent drug entrapment of different nanosuspension formulations (FG1-FG12) prepared by Combination technique 


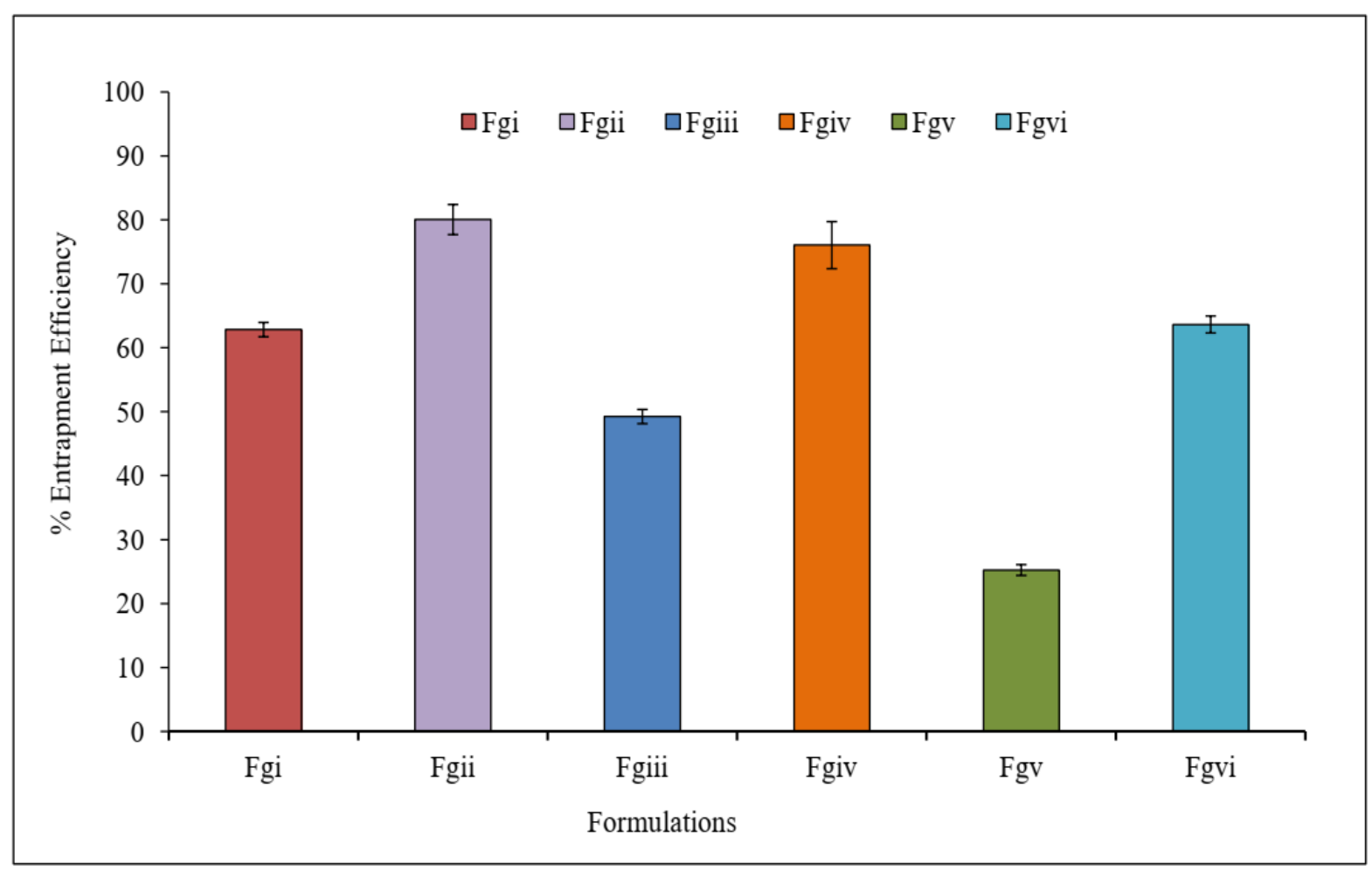

Fig. 2. Percent drug entrapment of different nanosuspension formulations (Fgi-Fgvi) prepared by Nanoprecipitation technique

It is visible in Table 3 (Combination technique) that on keeping amount of drug and homogenization speed constant and by selecting minimum amount $(10 \mathrm{mg})$ of polymers PEG6000, PVPK30 and PEG400, the highest \%EE i.e. 82.04\%, 78.44\% and $55.61 \%$, respectively was observed. As the amount of these polymers were increased to $20 \mathrm{mg}$ and 30 $\mathrm{mg}$ then decrease in \%EE was observed. However, in case of combination of polymers (PEG400:PVPK30), the highest \%EE (77.24\%) was observed on $30 \mathrm{mg}$ of polymers and on decreasing the amount of combination of different polymers, lower \%EE was seen. Under Nanoprecipitation technique (Table 4), by selecting $20 \mathrm{mg}$ of polymers PEG6000, PVPK30 and PEG400, the highest \%EE i.e. 80.03\%, 76.01\% and 63.64\%, respectively was obtained. The increased drug entrapment efficiency was due to formation of polymeric matrix [22].

\subsection{Analysis of particle size and polydispersity index}

The effects of formulation variables like drug/polymer ratios on the physical characteristics of the prepared nanosuspensions and the in vitro drug release characteristics 
were studied. Nanosuspensions were analyzed for particle size and polydispersity index (PDI). The differences in the particle size of nanosuspension formulations prepared with variable ratios of polymer and drug were utilized to find out the optimized formulation. The particle sizes for FG1 nanosuspension were falling in the range of 129-180 nm with PDI of 0.253 while particle size for Fgii nanosuspension was found to be $72-383 \mathrm{~nm}$ with PDI 0.358 (Fig. 3A and B).
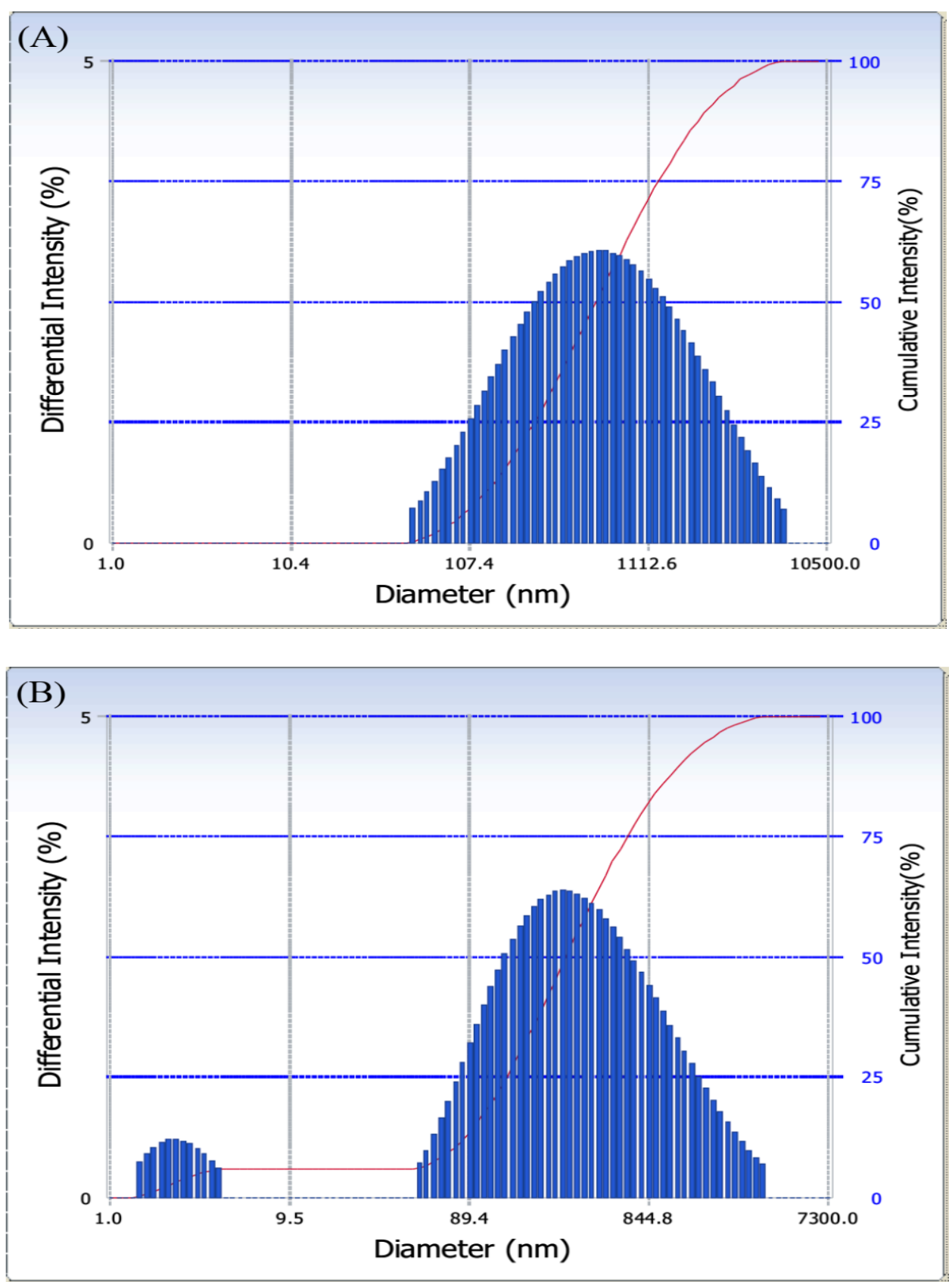

Fig. 3. Size distribution of optimized nanosuspension (A) Formulation FG1 and (B) Formulation Fgii 
In general, drug delivery systems with PDI value higher than 0.5 shows large size distributions and have the tendency to aggregate. Closer the value of PDI to zero, more will be the homogeneous nanosuspension formed [47]. The results projected the FG1 formulation prepared by combination technique as optimized formulation having average particle size 180 $\mathrm{nm}$ and PDI 0.253. The values of particle size and PDI revealed that the optimized nanosuspension formulation was found to be homogeneous with uniform distribution.

\subsection{Determination of zeta potential}

It is well known that particle size and zeta potential are significant characteristics, which suggest the physiochemical behaviors of the formulation, involving dissolution velocity, saturation solubility and physical stability. Zeta potential indicates the stability of the nanoparticles to be stably dispersed in suspension $[48,49]$.

Zeta potential was determined by measuring the electrophoretic mobility of particles in the electrical field using same instrument. The value of zeta potential is a judgment of the electrical charge at the surface of particles that ensures the physical stability of fabricated nanosuspensions [16]. A minimum zeta potential of $\pm 30 \mathrm{mv}$ is required where as in case of combined electrostatic or for steric stabilizer, a zeta potential of $\pm 20 \mathrm{mv}$ would be sufficient $[14,50]$. At $25{ }^{\circ} \mathrm{C}$ zeta value for formulation FG1 and Fgii was found to be $30.16 \mathrm{mV}$ and $22.19 \mathrm{mV}$, respectively. So it concludes that FG1 formulation having more stability as compared to Fgii formulation. The high value of zeta potential (more than $\pm 30 \mathrm{mV}$ ) shows electrostatic repulsion between particles. Electrostatic repulsion causes the particles to repel each other and avoids aggregation, which shows good stability. Zeta potentials of formulations FG1 and Fgii were shown in Fig. 4A and 4B, respectively. 

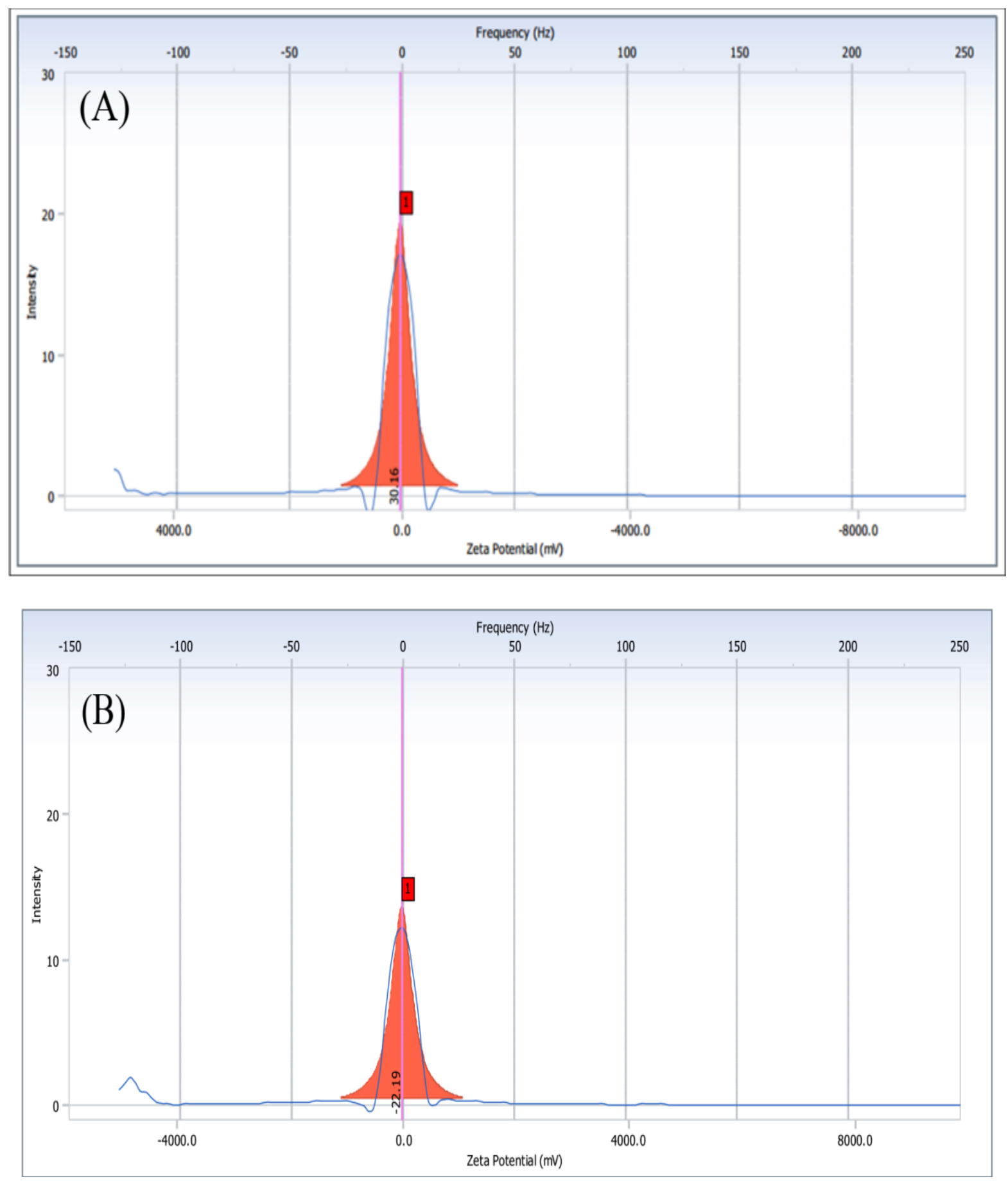

Fig. 4. Zeta potential of optimized nanosuspension (A) Formulation FG1 and (B) Formulation Fgii

\subsection{Transmission electron microscopy}

The TEM photomicrographs of GLM nanosuspensions (FG1 and Fgii) are shown in

Fig. 5A and B. The size of nanoparticles was found to be within the range of 20-100 nm. 

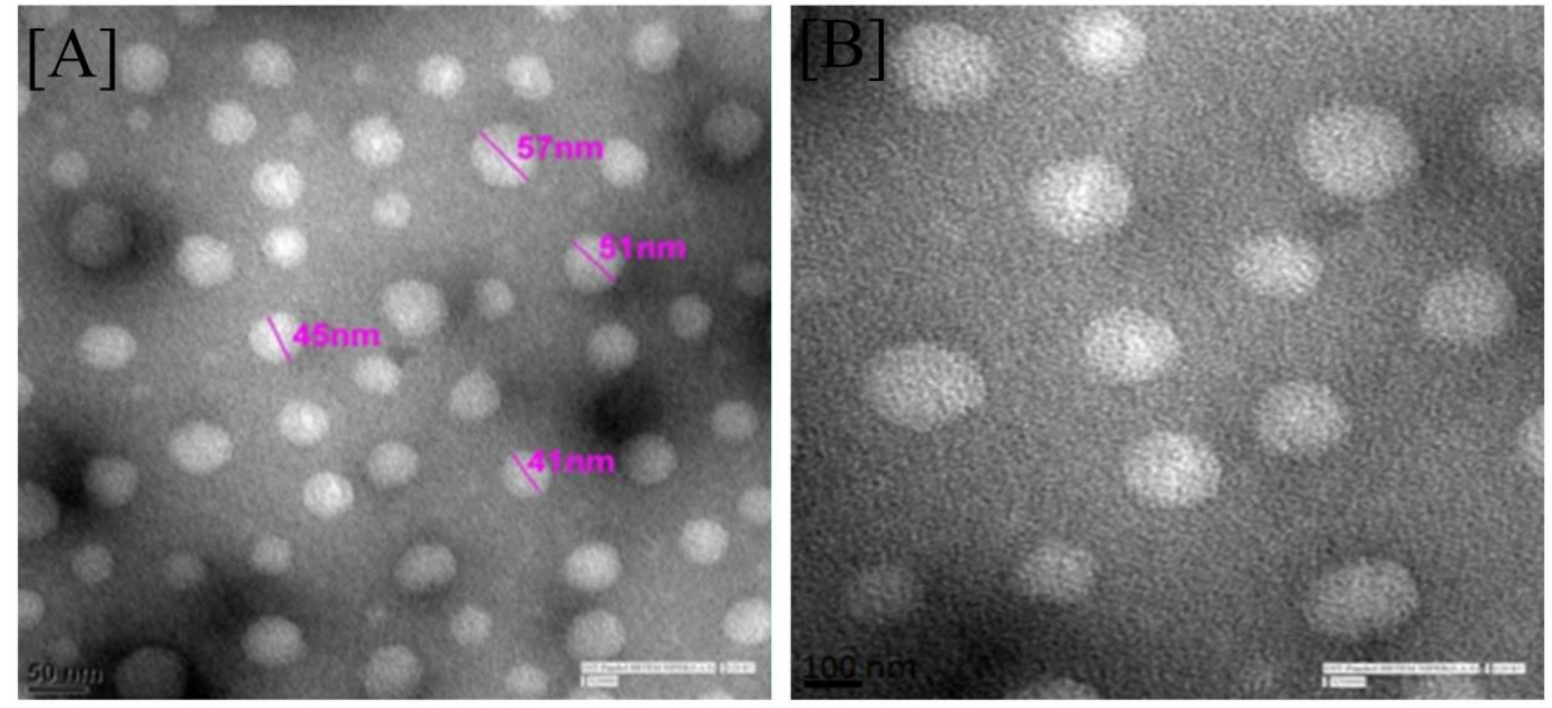

Fig. 5. TEM images of optimized nanosuspension (A) Formulation FG1 and (B) Formulation Fgii

\subsection{In vitro drug release studies}

The dissolution profiles of formulations FG1 and Fgii were observed. The comparative in vitro drug release profile of formulations FG1 and Fgii was shown in Fig. 6.

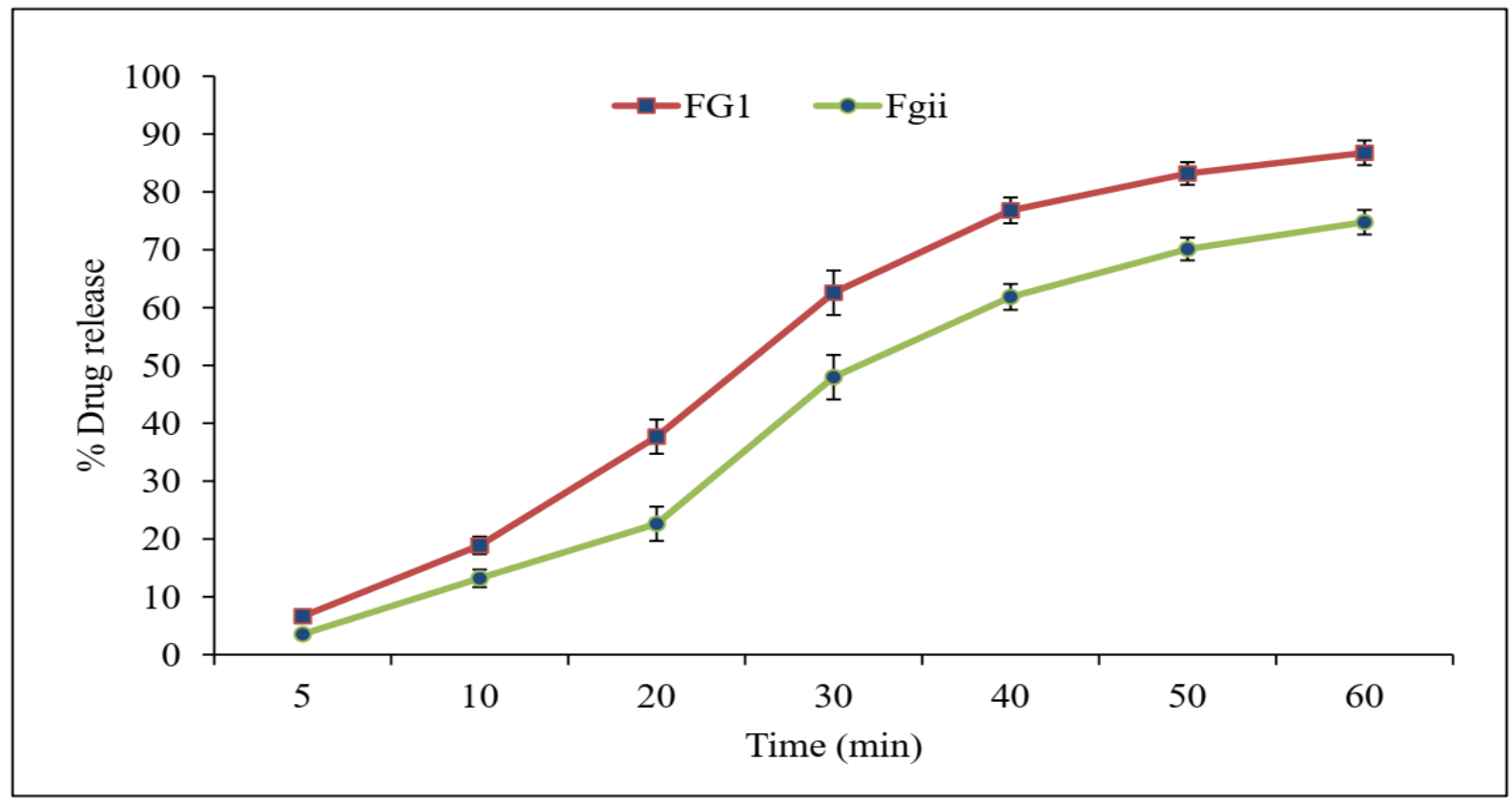

Fig. 6. Comparative drug release from nanosuspension formulation FG1 and formulation Fgii 
In 30 min more than $60 \%$ drug release was observed from FG1 formulation. The release was, however, sustained thereafter for the whole period of the study. The enhanced burst release can be attributed to leaching of drug from the polymer and increase in free drug content during. Another probable reason for enhanced burst release may be the erosion of nanoparticles $[14,51]$. The in vitro dissolution data revealed that formulation FG1 exhibited better drug release $(86.76 \%)$ as compared to that of formulation Fgii $(74.77 \%)$ after 60 min in PBS pH 6.8.

\section{Conclusion}

Glimepiride was selected as a model drug for treatment of diabetes. Two techniques such as combination technique, which included antisolvent evaporation followed by sonication and nanoprecipitation were selected for the preparation of nanosuspension by prescreening study. From literature review, the drug-polymer ratio was selected to use in preparation of nanosuspension formulations by both of the techniques. In combination technique 12 formulations and in nanoprecipitation method 6 formulations were prepared by varying the ratio of polymers like PEG6000, PEG400 and PVPK30 in 1:10, 1:20 and 1:30.

The optimized GLM containing nanosuspension formulations FG1 (combination technique) and Fgii (nanoprecipitation technique) demonstrated highest \%EE i.e. $82.04 \%$ and $80.03 \%$, respectively. The average particle size, zeta potential and PDI values for formulations FG1 and Fgii were found in the range of $129-180 \mathrm{~nm}, 30.16 \mathrm{mV}$ and 0.253 , and $72-383 \mathrm{~nm},-22.19 \mathrm{mV}$ and 0.358 , respectively. On the basis of these data, FG1 and Fgii formulations were selected for in vitro dissolution study.

The in vitro dissolution study revealed that FG1 formulation showed greater drug release i.e. $86.76 \%$ in comparison to Fgii formulation (74.77\%) after $60 \mathrm{~min}$ in PBS pH 6.8 . The formulation FG1 was studied for morphology by TEM, which ensured the formation of round nanoparticles. 
From the different studies carried out on nanosuspensions FG1 and Fgii prepared by two different techniques, it can be concluded that the formulation FG1 prepared by combination technique showed good solubility, dissolution and drug release as compared to formulation Fgii, prepared by nanoprecipitation technique. So, the present study concludes that the combination technique is found to be better technique to fabricate GLM nanosuspension as compared to nanoprecipitation technique.

Declarations of interest: The authors declare no conflict of interest, financial or otherwise.

\section{Research involving human participation and/or animals: None}

Informed consent: None

Ethical approval: This article does not contain any studies with animals or humans performed by any of the authors.

\section{References}

1. Sudhakar CK, Mishra V, Hemani V, Verma A, Jain A, Jain S, Charyulu RN. Reverse pharmacology of phytoconstituents of food and plant in the management of diabetes: Current status and perspectives. Trends Food Sci Technol. 2020. https://doi.org/10.1016/j.tifs.2020.10.024

2. Mishra V, Yadav N, Saraogi GK, Tambuwala MM, Giri N. Dendrimer based nanoarchitectures in diabetes management: An overview. Curr Pharm Design 2019; 25: $2569-2583$.

3. Ng LC, Gupta M. Transdermal drug delivery systems in diabetes management: A review. Asian J Pharm Sci. 2020; 15(1): 13-25.

4. Piero MN. Diabetes mellitus-A devastating metabolic disorder. Asian J Biomed Pharm Sci 2015; 4: 1-7.

5. Ozougwu J, Obimba $\mathrm{K}$, Belonwu C, Unakalamba $\mathrm{C}$. The pathogenesis and pathophysiology of type 1 and type 2 diabetes mellitus. J Physiol Pathophysiol 2013; 4: 46-57. 
6. Simos YV, Spyrou K, Patila M, Karouta N, Stamatis H, Gournis D, Dounousi E, Peschos D. Trends of nanotechnology in type 2 diabetes mellitus treatment. Asian J Pharm Sci. 2020. https://doi.org/10.1016/j.ajps.2020.05.001

7. Bansal G, Thanikachalam PV, Maurya RK, Chawla P, Ramamurthy S. An overview on medicinal perspective of thiazolidine-2, 4-dione: A remarkable scaffold in the treatment of type 2 diabetes. J Adv Res. 2020; 23: 163-205.

8. Kannan A, Kumar S. A study on drug utilization of oral hypoglycemic agents in type-2 diabetic patients. Asian J Pharm Clin Res 2011; 4: 60-64.

9. Mishra V, Gupta U, Jain NK. Biowaiver: an alternative to in vivo pharmacokinetic bioequivalence studies. Pharmazie 2010; 65(3): 155-161.

10. Bou-Chacra N, Melo KJ, Morales IA, Stippler ES, Kesisoglou F, Yazdanian M, Löbenberg R. Evolution of choice of solubility and dissolution media after two decades of biopharmaceutical classification system. The AAPS Journal. 2017; 19(4): 989-1001.

11. Daousani C, Macheras P. Biopharmaceutic classification of drugs revisited. Eur J Pharm Sci. 2016; 95: 82-87.

12. Charalabidis A, Sfouni M, Bergström C, Macheras P. The biopharmaceutics classification system (BCS) and the biopharmaceutics drug disposition classification system (BDDCS): beyond guidelines. Int J Pharm. 2019; 566: 264-281.

13. Park H, Seo HJ, Hong SH, Ha ES, Lee S, Kim JS, Baek IH, Kim MS, Hwang SJ. Characterization and therapeutic efficacy evaluation of glimepiride and L-arginine coamorphous formulation prepared by supercritical antisolvent process: Influence of molar ratio and preparation methods. Int J Pharm. 2020; 581: 119232.

14. Yadav SK, Mishra S, Mishra B. Eudragit-based nanosuspension of poorly water-soluble drug: Formulation and in vitro-in vivo evaluation. AAPS PharmSciTech 2012; 13(4): 1031-1044. 
15. Agrawal Y, Patel V. Nanosuspension: An approach to enhance solubility of drugs. J Adv Pharm Technol Res 2011; 2: 81-87.

16. Rahim H, Sadiq A, Khan S, Amin F, Ullah R, Shahat AA, Mahmood HM. Fabrication and characterization of glimepiride nanosuspension by ultrasonication-assisted precipitation for improvement of oral bioavailability and in vitro $\alpha$-glucosidase inhibition. Int J Nanomed 2019; 14: 6287-6296.

17. Jadhav P, Yadav A. Formulation, optimization, and in vitro evaluation of polymeric nanosuspension of flurbiprofen. Asian J Pharm Clin Res 2019; 12(11): 183-191.

18. Wang L, Du J, Zhou Y, Wang Y. Safety of nanosuspensions in drug delivery. Nanomedicine 2017; 13(2): 455-469.

19. Date AA, Halpert G, Babu T, Ortiz J, Kanvinde P, Dimitrion P, Narayan J, Zierden H, Betageri K, Musmanno O, Wiegand H. Mucus penetrating budesonide nanosuspension enema for local treatment of inflammatory bowel disease. Biomaterials 2018; 185: 97 105.

20. Ibrahim MA, Shazly GA, Aleanizy FS, Alqahtani FY, Elosaily GM. Formulation and evaluation of docetaxel nanosuspensions: in-vitro evaluation and cytotoxicity. Saudi Pharm J 2019; 27(1): 49-55.

21. Jacob S, Nair AB, Shah J. Emerging role of nanosuspensions in drug delivery systems. Biomat Res 2020; 24: 3.

22. Jassem NA, Rajab NA. Formulation and in vitro evaluation of azilsartan medoxomil nanosuspension. Int J Pharm Pharm Sci 2017; 9(7): 110-119.

23. Nakach M, Authelin JR, Perrin MA, Lakkireddy HR. Comparison of high pressure homogenization and stirred bead milling for the production of nano-crystalline suspensions. Int J Pharm 2018; 547: 61-71. 
24. Singh MK, Pooja D, Ravuri HG, Gunukula A, Kulhari H, Sistla R. Fabrication of surfactant-stabilized nanosuspension of naringenin to surpass its poor physiochemical properties and low oral bioavailability. Phytomedicine 2018; 40: 48-54.

25. Ferrar JA, Sellers BD, Chan C, Leung DH. Towards an improved understanding of drug excipient interactions to enable rapid optimization of nanosuspension formulations. Int $\mathbf{J}$ Pharm 2020; 578: 119094.

26. Phan ANQ, Bach LG, Nguyen TD, Le NTH. Efficient method for preparation of Rutin nanosuspension using chitosan and sodium tripolyphosphate crosslinker. J Nanosci Nanotechnol 2019; 19(2): 974-978.

27. Tehrani AA, Omranpoor MM, Vatanara A, Seyedabadi M, Ramezani V. Formation of nanosuspensions in bottom-up approach: theories and optimization. DARU J Pharm Sci $2019 ; 27: 451$.

28. Parve B, Shinde P, Rawat S, Rathod S, Waghmode G. Solubility enhancement techniques: A review. World J Pharm Pharm Sci 2014; 3: 400-422.

29. Patil MS, Godse SZ, Saudagar RB. Solubility enhancement by various techniques. World J Pharm Pharm Sci 2013; 2: 4558-4572.

30. Kadam S, Shinkar D, Saudagar R. Review on solubility enhancement techniques. Int J Pharm Biol Sci 2013; 3: 462-475.

31. Savjani KT, Gajjar AK, Savjani JK. Drug solubility: Importance and enhancement techniques. ISRN Pharmaceutics 2012; 195727.

32. Vimalson DC, Parimalakrishnan S, Jeganathan NS, Anbazhagan S. Techniques to enhance solubility of hydrophobic drugs: An overview. Asian J Pharm 2016; 10: S67S75.

33. Sinha B, Müller RH, Möschwitzer JP. Bottom-up approaches for preparing drug nanocrystals: Formulations and factors affecting particle size. Int J Pharm 2013; 453: 126-141. 
34. Mansouri M, Pouretedal HR, Vosoughi V. Preparation and characterization of Ibuprofen nanoparticles by using solvent/antisolvent precipitation. Open Conf Proc J 2011; 2: 8894.

35. Velmula M, Pavuluri P, Rajashekar S, Rao VUM. Nanosuspension technology for poorly soluble drugs-A Review. World J Pharm Pharm Sci 2015; 4: 1612-1625.

36. Arunkumar N, Deecaraman M, Rani C. Nanosuspension technology and its applications in drug delivery. Asian J Pharm 2011; 3: 1-5.

37. George M, Ghosh I. Identifying the correlation between drug/stabilizer properties and critical quality attributes (CQAs) of nanosuspension formulation prepared by wet media milling technology. Eur J Pharm Sci 2013; 48: 142-152.

38. Mishra V, Jain NK. Acetazolamide encapsulated dendritic nano-architectures for effective glaucoma management in rabbits. Int J Pharma 2014; 461: 380-390.

39. Bipul N, Satyabrat S. Compatibility studies of glimepiride with selected excipients for the development of extended release formulations. Int J Pharm Bio Sci 2016; 6(2): 3748.

40. Indian Pharmacopoeia. The Indian Pharmacopoeia Commission, Ghaziabad, India, 2007, $1, \mathrm{pp} 153$.

41. Lu Y, Wang ZH, Li T, McNally H, Park K, Sturek M. Development and evaluation of transferrin-stabilized paclitaxel nanocrytal formulation. J Control Release 2014; 176: 7685.

42. Kumar BP, Baig AA. Formulation and evaluation of pitavastatin nanosuspension. J Chem Pharm Sci 2014; 7: 330-335.

43. Ethiraj T, Sujitha R, Ganesan V. Formulation and in-vitro evaluation of nanosuspension of glimepiride. Int J Pharm 2013; 3: 122-133. 
44. Cho H, Kang J, Ngo L, Tran P, Lee Y. Preparation and evaluation of solid-selfemulsifying drug delivery system containing paclitaxel for lymphatic delivery. $\mathrm{J}$ Nanomat 2016; 3642418.

45. Sharma M, Bilandi A, Kataria MK. A research on formulation and evaluation of floating microspheres of glimepiride. World J Pharm Pharm Sci 2015; 4: 1298-1317.

46. Mishra V, Bansal KK, Verma A, Yadav N, Thakur S, Sudhakar K, Rosenholm JM. Solid lipid nanoparticles: Emerging colloidal nano drug delivery systems. Pharmaceutics 2018; 10: $191-212$.

47. Chaudhary SK, Mahmoudi N, Rao PB, Chakraborty J. Aceclofenac nanosuspension: Formulation and evaluation. Unique J Pharm Bio Sci 2016; 4: 11-19.

48. Li S, Zhang J, Fang Y, Yi J, Lu Z, Chen Y, Guo B. Enhancing betulinic acid dissolution rate and improving antitumor activity via nanosuspension constructed by anti-solvent technique. Drug Design Develop Ther 2020; 14: 243-256.

49. Kathpalia H, Juvekar S, Shidhaye S. Design and in vitro evaluation of atovaquone nanosuspension prepared by $\mathrm{pH}$ based and anti-solvent based precipitation method. Colloid Interface Sci Commun 2019; 29: 26-32.

50. Kotecha RK, Bhadra S, Rajesh KS. Formulation and process development of azithromycin ophthalmic nanosuspension. Int J Pharm Pharm Sci 2013; 5: 490-497.

51. Dandagi P, Kerur S, Mastiholimath V, Gadad A, Kulkarni A. Polymeric ocular nanosuspension for controlled release of acyclovir: in vitro release and ocular distribution. Iranian J Pharm Res 2009; 8(2): 79-86. 


\section{Highlights}

- Sulphonylureas are class first oral hypoglycemic drugs.

- Glimepiride of BCS class-II is mostly used in treatment of type-2 diabetes mellitus

- Nanosuspensions improve the solubility of the drugs.

- Comparison of glimepiride nanosuspensions prepared by different techniques. 


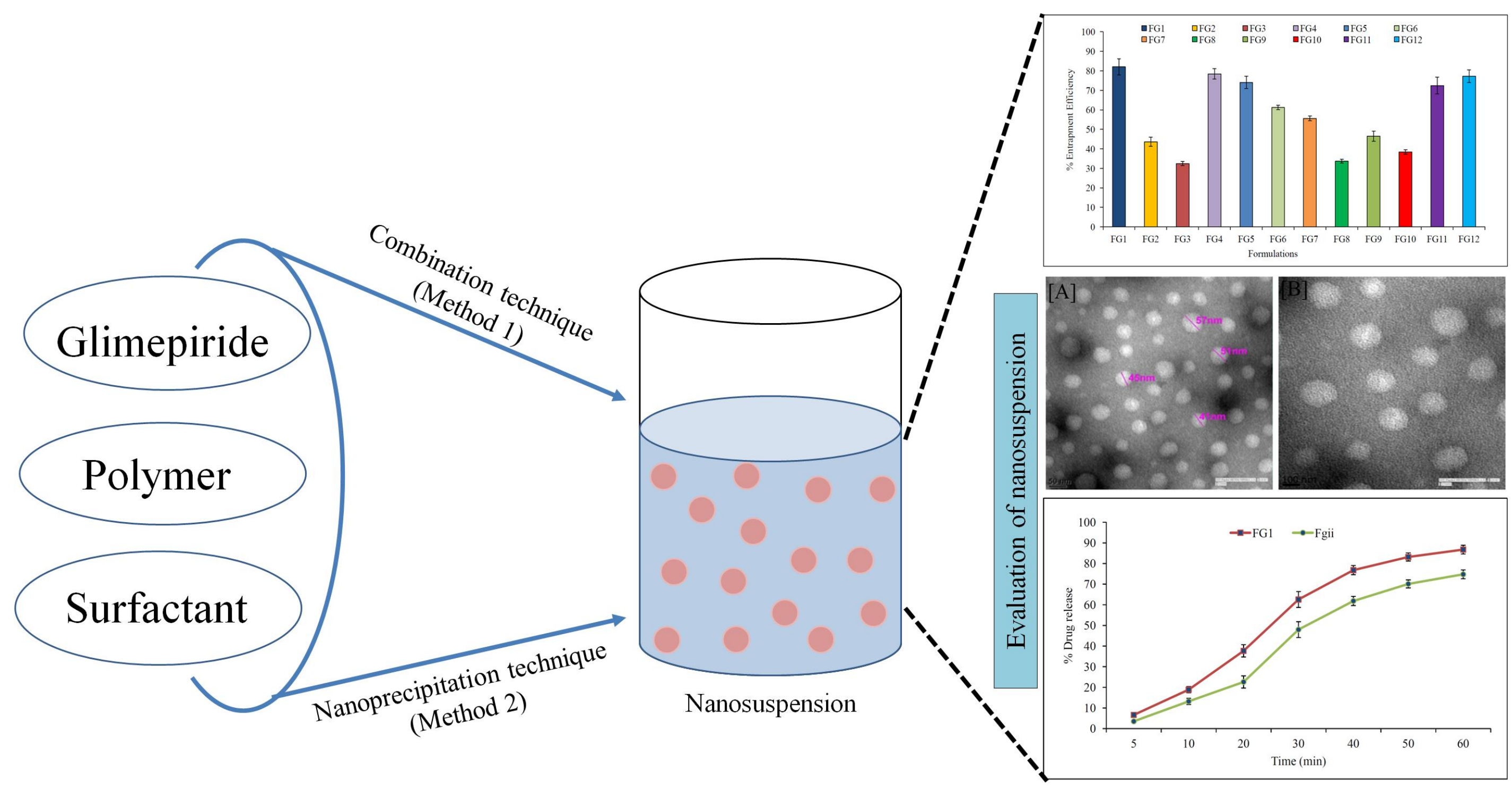




\section{Supporting Information}

Table S1 Compatibility studies of drug-excipient in 1:1 ratio at different time intervals

\begin{tabular}{|c|c|c|c|c|c|}
\hline Features & $1^{\text {st }}$ Day & $2^{\text {nd }}$ Day & $3^{\text {rd }}$ Day & 10 $^{\text {th }}$ Day & $15^{\text {th }}$ Day \\
\hline \multicolumn{6}{|c|}{ Glimepiride:PEG6000 } \\
\hline Color & White & $\sqrt{ }$ & $\sqrt{ }$ & $\sqrt{ }$ & $\sqrt{ }$ \\
\hline Appearance & Crystalline & $\sqrt{ }$ & $\sqrt{ }$ & $\sqrt{ }$ & $\sqrt{ }$ \\
\hline State & Solid & $\sqrt{ }$ & $\sqrt{ }$ & $\sqrt{ }$ & $\sqrt{ }$ \\
\hline Lumps & Not present & $\sqrt{ }$ & $\sqrt{ }$ & $\sqrt{ }$ & $\sqrt{ }$ \\
\hline \multicolumn{6}{|c|}{ Glimepiride:PVPK30 } \\
\hline Color & White & $\sqrt{ }$ & $\sqrt{ }$ & $\sqrt{ }$ & $\sqrt{ }$ \\
\hline Appearance & Crystalline & $\sqrt{ }$ & $\sqrt{ }$ & $\sqrt{ }$ & $\sqrt{ }$ \\
\hline State & Solid & $\sqrt{ }$ & $\sqrt{ }$ & $\sqrt{ }$ & $\sqrt{ }$ \\
\hline Lumps & Not present & $\sqrt{ }$ & $\sqrt{ }$ & $\sqrt{ }$ & $\sqrt{ }$ \\
\hline \multicolumn{6}{|c|}{ Glimepiride:SLS } \\
\hline Color & White & $\sqrt{ }$ & $\sqrt{ }$ & $\sqrt{ }$ & $\sqrt{ }$ \\
\hline Appearance & Crystalline & $\sqrt{ }$ & $\sqrt{ }$ & $\sqrt{ }$ & $\sqrt{ }$ \\
\hline State & Solid & $\sqrt{ }$ & $\sqrt{ }$ & $\sqrt{ }$ & $\sqrt{ }$ \\
\hline Lumps & Not present & $\sqrt{ }$ & $\sqrt{ }$ & $\sqrt{ }$ & $\sqrt{ }$ \\
\hline \multicolumn{6}{|c|}{ Glimepiride:PEG6000:PVPK30 } \\
\hline Color & White & $\sqrt{ }$ & $\sqrt{ }$ & $\sqrt{ }$ & $\sqrt{ }$ \\
\hline Appearance & Crystalline & $\sqrt{ }$ & $\sqrt{ }$ & $\sqrt{ }$ & $\sqrt{ }$ \\
\hline State & Solid & $\sqrt{ }$ & $\sqrt{ }$ & $\sqrt{ }$ & $\sqrt{ }$ \\
\hline Lumps & Not present & $\sqrt{ }$ & $\sqrt{ }$ & $\sqrt{ }$ & $\sqrt{ }$ \\
\hline \multicolumn{6}{|c|}{ Glimepiride:PEG6000:SLS } \\
\hline
\end{tabular}




\begin{tabular}{|c|c|c|c|c|c|}
\hline Color & White & $\sqrt{ }$ & $\sqrt{ }$ & $\sqrt{ }$ & $\sqrt{ }$ \\
\hline Appearance & Crystalline & $\sqrt{ }$ & $\sqrt{ }$ & $\sqrt{ }$ & $\sqrt{ }$ \\
\hline State & Solid & $\sqrt{ }$ & $\sqrt{ }$ & $\sqrt{ }$ & $\sqrt{ }$ \\
\hline Lumps & Not present & $\sqrt{ }$ & $\sqrt{ }$ & $\sqrt{ }$ & $\sqrt{ }$ \\
\hline \multicolumn{6}{|c|}{ Glimepiride:PVPK30:SLS } \\
\hline Color & White & $\sqrt{ }$ & $\sqrt{ }$ & $\sqrt{ }$ & $\sqrt{ }$ \\
\hline Appearance & Crystalline & $\sqrt{ }$ & $\sqrt{ }$ & $\sqrt{ }$ & $\sqrt{ }$ \\
\hline State & Solid & $\sqrt{ }$ & $\sqrt{ }$ & $\sqrt{ }$ & $\sqrt{ }$ \\
\hline Lumps & Not present & $\sqrt{ }$ & $\sqrt{ }$ & $\sqrt{ }$ & $\sqrt{ }$ \\
\hline \multicolumn{6}{|c|}{ Glimepiride:SLS:PVPK30:PEG6000 } \\
\hline Color & White & $\sqrt{ }$ & $\sqrt{ }$ & $\sqrt{ }$ & $\sqrt{ }$ \\
\hline Appearance & Crystalline & $\sqrt{ }$ & $\sqrt{ }$ & $\sqrt{ }$ & $\sqrt{ }$ \\
\hline State & Solid & $\sqrt{ }$ & $\sqrt{ }$ & $\sqrt{ }$ & $\sqrt{ }$ \\
\hline Lumps & Not present & $\sqrt{ }$ & $\sqrt{ }$ & $\sqrt{ }$ & $\sqrt{ }$ \\
\hline
\end{tabular}

Where $\sqrt{ }$ represents No change from initial observation 


\section{Drug-polymer compatibility study}

Fourier transform infrared (FTIR) spectrum of pure glimepiride exhibited characteristic sharp peaks at $3369 \mathrm{~cm}^{-1}$ and $3288 \mathrm{~cm}^{-1}$ of $\mathrm{N}-\mathrm{H}$ stretching, $1707 \mathrm{~cm}^{-1}$ and $1674 \mathrm{~cm}^{-1}$ of carbonyl group, $1345 \mathrm{~cm}^{-1}$ of C-N stretching vibration, and $1153 \mathrm{~cm}^{-1}$ of $\mathrm{S}=\mathrm{O}$ stretching vibration.

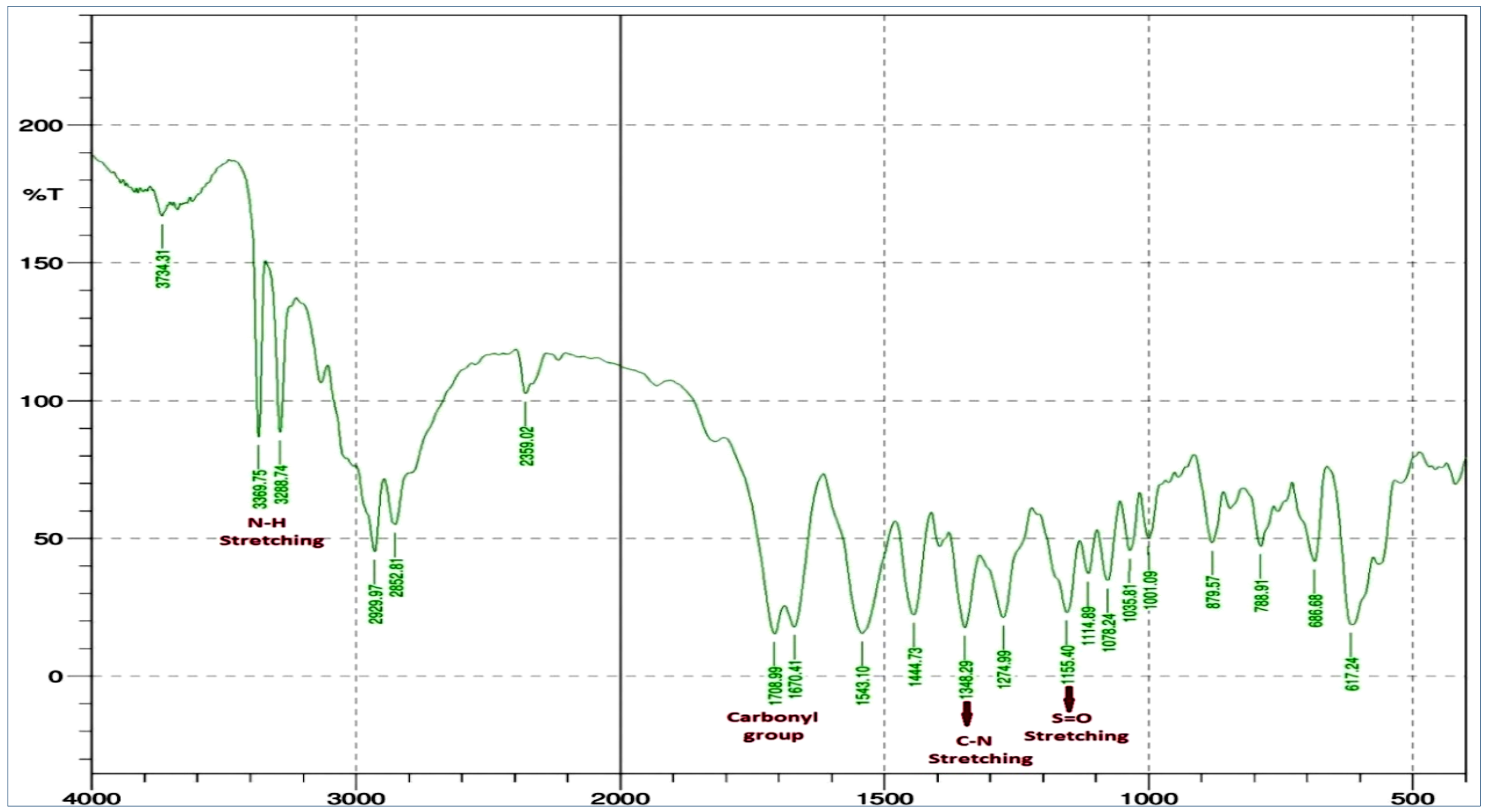

Fig. S1 FTIR spectrum of glimepiride 

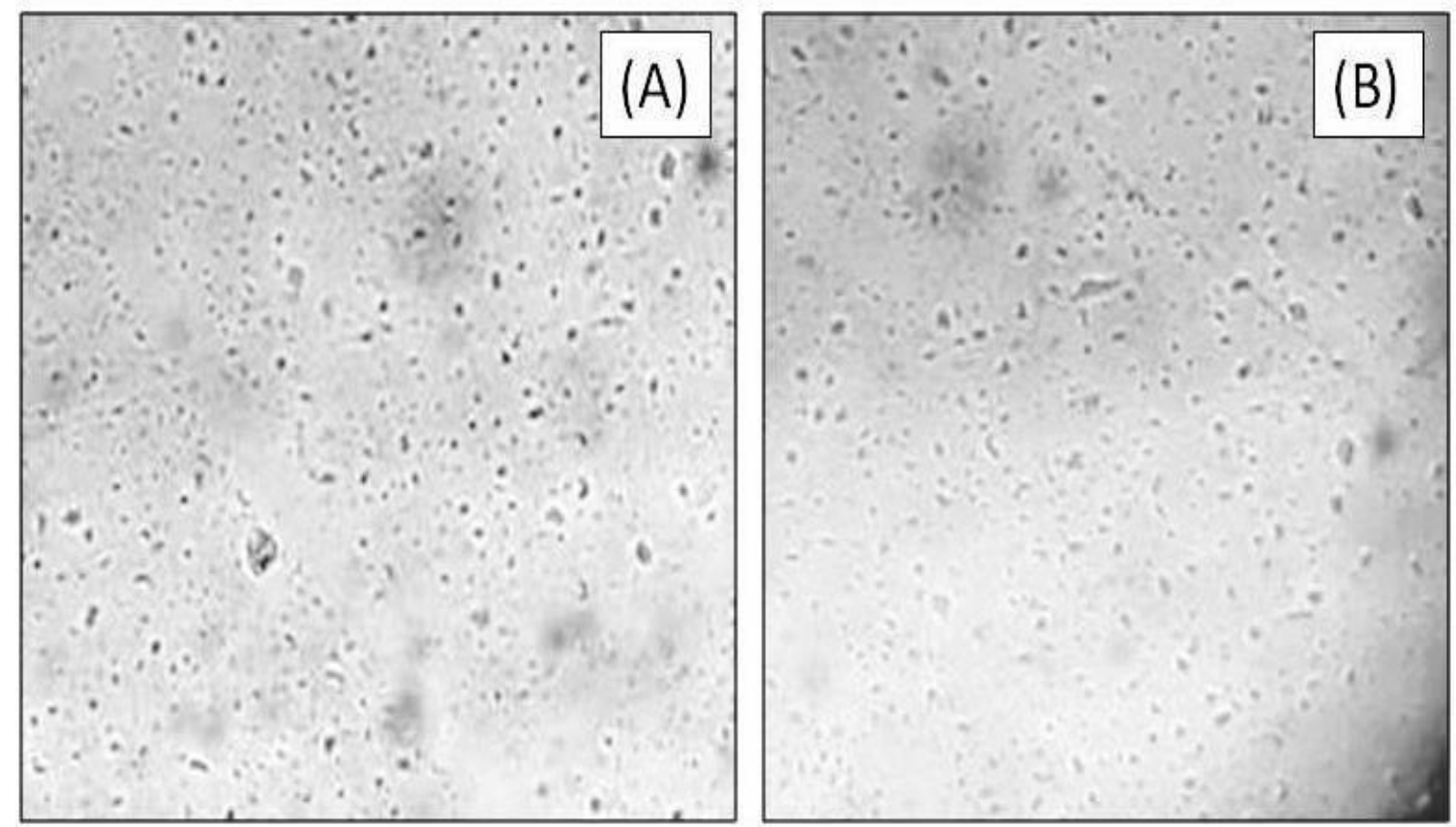

Fig. S2. Optical photomicrographs of nanosuspension (A) Formulation FG1 and (B)

Formulation Fgii at 450X magnification 


\section{Credit author statement}

Sujit Bose: Conceptualization, Writing - original draft; Pooja Sharma: Data curation; Vijay Mishra: Formal analysis, Writing - review \& editing, Supervision; Swati Patial: Methodology;

Gaurav K. Saraogi: Writing - review \& editing; Murtaza M. Tambuwala: Writing - review \& editing; Kamal Dua: Writing - review \& editing 


\section{Declaration of interests}

$\checkmark \quad \square$ The authors declare that they have no known competing financial interests or personal relationships that could have appeared to influence the work reported in this paper.

$\square$ The authors declare the following financial interests/personal relationships which may be considered as potential competing interests:

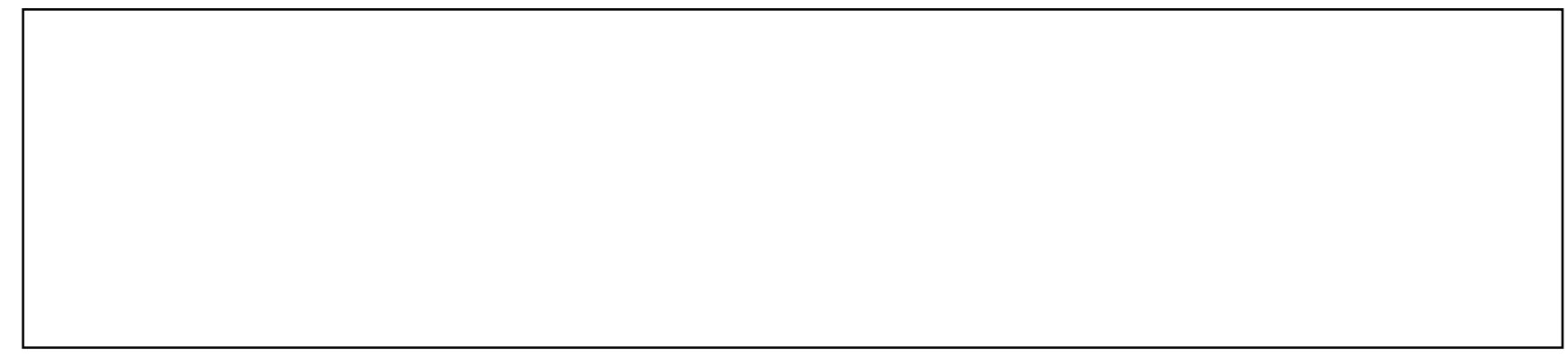

